\title{
Processo de aprendizagem da docência: narrativas de uma licencianda no PIBID
}

\author{
Ayla Moulaz Carvalho \\ Miriam Cardoso Utsumi
}

\section{Resumo}

O presente estudo teve por objetivo investigar as contribuições do subprojeto de Matemática do PIBID de uma Instituição de Ensino Superior pública de uma cidade do Interior do Estado de São Paulo, analisando as ações pedagógicas de uma licencianda durante o seu processo de aprendizagem da docência como participante do Programa. Trata-se de uma pesquisa descritiva que se utilizou de análise documental. A análise dos dados revelou um equilíbrio nos fragmentos que se referem a gestão do ensino e a gestão da aprendizagem, com prevalência nesta última, o que é discordante dos resultados de estudos anteriores realizados com licenciandos. Tal fato sugere uma contribuição do PIBID com relação a preocupação, não somente com a gestão do ensino, mas principalmente com a gestão da aprendizagem dos estudantes, o que certamente acarretará em uma melhor formação inicial. Além disso, encontramos elementos que nos permitiram afirmar que o PIBID contribuiu com o desenvolvimento das competências elencadas pelas Diretrizes Curriculares para os cursos de Matemática, a saber: elaborar propostas de ensino-aprendizagem e analisar criticamente propostas curriculares de Matemática para a educação básica; analisar, selecionar e produzir materiais didáticos; desenvolver estratégias de ensino que favoreçam a criatividade, a autonomia e a flexibilidade do pensamento matemático dos estudantes; perceber a prática docente de Matemática como um processo dinâmico, carregado de incertezas e conflitos, um espaço de criação e reflexão; contribuir para a realização de projetos coletivos dentro da escola básica.

Palavras chave: Educação matemática; Aprendizagem da docência; PIBID 


\title{
The learning process of how to teach: undergraduate's narratives on PIBID
}

\author{
Ayla Moulaz Carvalho \\ Miriam Cardoso Utsumi
}

Abstract

This study was conducted with the purpose of investigating the contributions of a public higher education institution's PIBID Mathematics project. The study analyzed the teaching skills of a student from the aforementioned institution during her participation in the Program. The descriptive research was performed applying documental analysis, which showed a balance between competences to teach, and abilities to plan the students' learn. This result is different of previous studies conducted with students in other teacher education programs. This fact suggests a PIBID's contribution to the participant's development which will result in a better initial qualification. Moreover, this study allowed for the confirmation of PIBID's contribution to the development of the mathematical practices established by the Curricular Guidelines for Mathematics Courses, which follow: create teaching-learning plans and critically analyze the Mathematics curriculum for basic education; analyze, select and produce learning materials; develop teaching strategies that highlight creativity, autonomy and the flexibility of students' logico-mathematical thinking; perceive the teaching of Mathematics as a dynamic process that carries within conflicts and uncertainties, but also opens up space for reflection and creativity; and, contribute to the implementation of collaborative projects during elementary and middle education.

Keywords: Mathematics education; Learning process of how to teach; PIBID 


\section{Introdução}

Segundo a Organização para Cooperação e Desenvolvimento Econômico - OCDE, a melhoria da eficácia do ensino passa, em grande parte, pela capacidade de atrair indivíduos competentes para o magistério. Essa organização também preconiza que seu ensino seja de alta qualidade e acessível a todos os alunos (OCDE, 2005, como citado por LESSARD, 2006).

Segundo a referida organização, a única variável de peso que influencia os resultados dos alunos em geral é a qualidade do docente. Esta constatação pode explicar as pressões e exigências atuais de todos os países para a melhoria da qualidade da formação de seus professores.

No Brasil, as Diretrizes Curriculares para os cursos de Matemática (BRASIL, 2001, p. 4) orientam a formação de professores de modo que o licenciando venha a adquirir, dentre outras, as capacidades de:

analisar criticamente propostas curriculares de Matemática para a educação básica; desenvolver estratégias de ensino que favoreçam a criatividade, a autonomia e a flexibilidade do pensamento matemático dos educandos, buscando trabalhar com mais ênfase nos conceitos do que nas técnicas, fórmulas e algoritmos; perceber a prática docente de Matemática como um processo dinâmico, carregado de incertezas e conflitos, um espaço de criação e reflexão, onde novos conhecimentos são gerados e modificados continuamente (...)

Entendemos como Arruda e outros (2011) que as tarefas essenciais do futuro professor seriam gerenciar suas relações com três tipos de saberes docentes: o saber disciplinar (o conteúdo), o saber pedagógico (o ensino) e o saber didático (o aprendizado). Porém, como afirma Calderano (2012) a formação inicial, não atende adequadamente às demandas do mundo do trabalho no que tange à educação.

Em vários estudos realizados (ANDRÉ e outros, 1999; CURI, 2000; GATTI E BARRETO, 2009; GATTI, 2012), verifica-se que as escolas de formação inicial de professores de Matemática deixam muito a desejar.

De acordo com Gatti e Barreto (2009) e Gatti (2014), ainda se verificam cursos com ausência de perfil profissional claro de professor; currículos que não se voltam para as questões da prática docente ou aos seus fundamentos metodológicos; estruturas curriculares fragmentadas, sem disciplinas articuladoras e com ementas genéricas; estágios obrigatórios fragilizados sem vinculação clara com os sistemas escolares e sem explicitação das formas de supervisão; formação à base de apostilas e resumos, evidenciando precariedade de conhecimentos para um grupo que, em grande parte, cursou o ensino médio na escola pública, além de predominância da área específica em detrimento dos conhecimentos pedagógicos e pouco preparo dos professores das Instituições de Ensino Superior para atuar na formação de professores. 
Tais fatos se configuram num problema sério para o ensino, pois acredita-se, como Rasmussem (2008, p.12), que "o professor eficiente e profissional que trabalha para propiciar a aprendizagem de seus alunos precisa possuir a combinação adequada entre conhecimento profissional e conhecimento didático". Ou seja, o conhecimento do conteúdo específico é necessário, mas não suficiente para garantir que o que for ensinado será aprendido. Os professores necessitam ir além da compreensão pessoal da matéria que ensinam, eles necessitam de uma compreensão especializada para que consigam criar as condições para que a maioria de seus alunos aprenda.

Dessa forma, pode-se inferir que, como afirma Tardif (2002), o professor ideal é aquele que domina os conhecimentos relativos à área em que atua, à disciplina e ao programa conforme consta no currículo; tem conhecimentos relativos às Ciências da Educação e à Pedagogia e, desenvolve um saber prático a partir da reflexão sobre suas experiências.

A preocupação social também figura entre as características desejáveis aos futuros professores de Matemática, como revelado pelas Diretrizes Curriculares para cursos de Matemática (BRASIL, 2001, p. 3), cujo licenciando deve ter:

visão de seu papel social de educador e capacidade de se inserir em diversas realidades com sensibilidade para interpretar as ações dos educandos; visão da contribuição que a aprendizagem da Matemática pode oferecer à formação dos indivíduos para o exercício da cidadania; e, visão de que o conhecimento matemático pode e deve ser acessível para todos (...).

Tais características compreendem o perfil do futuro profissional. No entanto, para aqueles que ainda não exercem o magistério, o Programa Institucional de Bolsas de Iniciação à Docência (PIBID) se apresenta como uma oportunidade de aprendizagem da profissão docente e de construção da identidade profissional, além de possibilitar ao licenciando uma inserção no cotidiano escolar, de forma mais colaborativa e com apoio da Universidade e da Escola Campo.

O PIBID é uma política pública do governo federal, iniciada em 2007, que tem como foco a elevação da qualidade das ações acadêmicas voltadas à formação inicial de professores nos cursos de licenciatura das Instituições de Ensino Superior e a inserção do licenciando no cotidiano de escolas da rede pública de ensino, visando o desenvolvimento de práticas inovadoras, o que promove a integração entre educação superior e educação básica. A escola entra como campo de ação e de investigação colaborativa.

Algumas das experiências do Programa vêm sendo investigadas: Tinti (2012) e Correia (2012), por exemplo, realizaram suas investigações no mesmo subprojeto do PIBID, de uma Instituição particular de Ensino Superior do Estado de São Paulo. Os dados obtidos 
por Tinti (2012) sobre as contribuições do PIBID para a formação de professores de matemática evidenciaram que o subprojeto analisado teve como ações iniciais o conhecimento do contexto escolar, a elaboração de relatórios, a constituição de grupos de trabalho interdisciplinar e a realização de reuniões de socialização e reflexão, apontando que tais ações contribuíram para a superação de pré-conceitos negativos em relação ao sistema público de ensino e à minimização do choque de realidade vivenciado nos primeiros anos de atuação profissional.

Correia (2012), por sua vez, investigou qualitativamente os conhecimentos evidenciados pelos licenciandos em Matemática e Física, após o desenvolvimento de suas atividades de intervenção nas escolas. A pesquisa identificou alguns conhecimentos evidenciados pelos bolsistas do PIBID, destacando o conhecimento de conteúdo, o conhecimento pedagógico geral e o conhecimento pedagógico de conteúdo, apontando, ainda, o conhecimento curricular, o conhecimento do contexto educacional e o conhecimento sobre os alunos e suas características.

Os estudos revistos trazem, majoritariamente, pontos positivos em detrimento dos negativos em relação ao programa, mostrando a abrangência de sua aprovação, principalmente no que diz respeito à formação inicial de professores, tendo em vista a importância desta prática para o exercício da docência. Canan (2012), por exemplo, relata uma investigação com licenciandos dos cursos de Pedagogia, Ciências Biológicas, Matemática e Letras, da Universidade Regional Integrada do Alto Uruguai e das Missões (URI) - campus de Frederico Westphalen, que revelou como a primeira experiência proporcionada pelo PIBID foi positiva por mostrar o quão desafiador e complexo é o ser professor.

Ambrosetti, Arruda, Almeida, Calil e Passos (2013), destacaram que “(...) a aprendizagem da docência se desenvolve melhor quando futuros professores trabalham de perto com professores experientes e com alunos para experimentar o que eles estão aprendendo" (p. 156).

Analogamente, Flores (2010, como citado por RAUSCH e FRANTZ, 2013) sugere que se essa troca de experiências acontecesse, haveria amenização do choque causado pela socialização profissional ocorrida na escola no momento de incursão do novo docente, reforçando crenças e teorias implícitas.

O espaço escolar passa, então, a ser percebido não somente como um lugar de formação, mas também como uma oportunidade de realização profissional (NEITZEL, FERREIRA E COSTA, 2013), contribuindo para a "superação de pré-conceitos negativos em relação ao sistema público de ensino" (TINTI, 2012, p. 12).

O PIBID torna-se, assim, um programa atrativo como motivador para a docência durante a graduação, contribuindo para a valorização da profissão docente (CANAN, 2012). 
Outra importante contribuição que o PIBID tem fornecido é a parceria entre Universidade e Escola (ZAQUEU, 2014), também constatada por Neitzel, Ferreira e Costa (2013), que observaram o apoio científico-pedagógico da universidade e a interação entre os saberes da experiência e os saberes do campo acadêmico em sua investigação.

Por outro lado, temos estudos como o de dos Santos Felício (2014) que alertam para o fato de que somente o PIBID não é suficiente para atingir os objetivos de incentivar a formação de professores para a Educação Básica:

Existe, por parte dos licenciandos, o reconhecimento de que o PIBID é um programa fundamental que contribui para a formação do professor. Contudo, ressaltam que essa contribuição não se relaciona necessariamente à docência na Educação Básica. O nível universitário está sendo almejado pelos licenciandos que experienciam o PIBID, evidenciando que não basta um programa para incentivar a profissão docente naquele nível de ensino que precisa ser mais atrativa (p. 431).

Corroboram essa visão Obara, Broietti e Passos (2017) cuja pesquisa trouxe à tona o fato de que muitos ex-bolsistas do PIBID não estavam atuando no magistério. O PIBID, como política pública, segundo os pesquisadores, tem se mostrado necessário, mas não suficiente para tornar a carreira docente mais atrativa.

Concordamos com Rodrigues, Miskulin e Silva (2017) sobre a necessidade de serem oferecidos salários dignos, planos de carreira, entre outras condições básicas para tornar a carreira docente atrativa, o que consequentemente poderá ser fator de incentivo para que muitos jovens se interessem pela profissão docente.

Além de se interessar pela profissão, esse jovem deve ser capaz de mobilizar os interesses dos seus futuros educandos para a aprendizagem. Em virtude da evolução tecnológica, a sociedade, ao longo do processo histórico, está se transformando: o conhecimento ultrapassou os prédios escolares por meio das tecnologias de comunicação e informação - TIC o que evidencia com mais clareza a necessidade de redefinição do papel da escola e do professor.

A transformação da escola entra em sala de aula através da reestruturação do papel do professor na era digital. Nesse cenário, se modificam “...os eixos do ensinar para optar pelos caminhos do aprender", onde professores e alunos estejam engajados no processo de aprender a aprender (BEHRENS, 2013, p.79).

Segundo Silva (2016), a ideia de sermos apenas usuários dos meios tecnológicos deve ser revista pela escola. Um dos papéis da escola na era digital é o de implementar o computador, como uma ferramenta não apenas capaz de obter informações e conhecimentos ou promover o acesso à comunicação, mas que dá suporte para a produção de novos conhecimentos. 
Mais do que dominar o conhecimento operacional, o profissional educador deve criar condições de aprendizagem. A pesquisadora citada relata uma experiência com o uso do Geogebra no Ensino Médio.

Segundo Valente (1993, p.6), “...o professor precisa deixar de ser o repassador de conhecimento [...] e passar a ser criador de ambientes de aprendizagem e o facilitador do processo de desenvolvimento intelectual do aluno".

Nesse contexto, cabe ao professor buscar conhecimentos que possam ser utilizados como recursos auxiliadores, que favoreçam positivamente as suas aulas, o tornando mediador no processo ensino-aprendizagem.

Destarte as considerações realizadas, o presente artigo tem por objetivo investigar as contribuições do subprojeto de Matemática do PIBID de uma Instituição pública de Ensino Superior de uma cidade do Interior do Estado de São Paulo, analisando o processo de aprendizagem da docência, concepções, obstáculos e superações vivenciadas por uma licencianda, durante sua participação no Programa, por meio das narrativas constantes em seus relatórios.

A análise de narrativas é um tipo de pesquisa narrativa que, segundo Hatch e Wisniewski (como citados por FREITAS e FIORENTINI, 2007, p. 66), usa “...narrativas (histórias) como dados de pesquisa e produzem taxonomias e categorias" para desenvolver tais análises.

As narrativas ou escritas discursivas têm sido relatadas na literatura (BOGDAN E BIKLEN, 1994; FREITAS, 2000; FREITAS E FIORENTINI, 2008) como estratégias significativas de formação inicial e continuada de professores.

Santos (2008) afirma que, se direcionadas e sistematizadas, elas criam condições para a reflexão sobre a prática docente naqueles contextos de formação porque “... as vidas dos professores estão cruzadas com a história da sociedade, da escola enquanto instituição educadora e da profissão, possibilitando compreender a dimensão singular e complexa da ação docente e ressignificar os processos formativos (Santos, 2008, p. 211)”.

As narrativas ainda, de acordo com Freitas e Fiorentini (2007), oferecem àquele que narra e/ou investiga uma chance de pensar com mais profundidade, produzindo e sistematizando lembranças que por vezes tendem a ser esquecidas.

Desenvolver uma compreensão sobre esse processo de aprendizagem pode criar condições para a emergência de uma consciência ampliada no que se refere a processos concretos de decisão sobre os limites e possibilidades de tal Programa para a formação inicial docente e constituir-se em fonte para reflexões acadêmicas e políticas, como também para o aprimoramento do Programa e da estrutura curricular do Curso. 


\section{Metodologia}

Trata-se de uma pesquisa descritiva, em que os documentos, objetos de análise, são as narrativas constantes nos relatórios de uma licencianda participante do PIBID de Matemática de uma universidade pública do interior do Estado de São Paulo.

O subprojeto do PIBID em questão está em vigor desde julho de 2011, tendo sido aprovado pelo Edital 18/2010, contemplando 23 bolsistas de iniciação à docência. O subprojeto atendia duas escolas, até o primeiro semestre de 2012, passando a atender três escolas, a partir do segundo semestre de 2012 e até o primeiro semestre de 2015, quando volta a atender duas escolas. O objetivo geral do subprojeto é utilizar as Tecnologias da Informação e Comunicação - TIC numa perspectiva de investigação e colaboração, de forma a colocar os conhecimentos matemáticos e científicos ao alcance de todos: professores, licenciandos e alunos da escola básica.

Obteve-se acesso aos relatórios dos PIBIDianos de Matemática, no período de 2012 a 2016. Esses relatórios eram entregues semestralmente à coordenadora de área do projeto para composição do relatório Institucional enviado a Coordenação de Aperfeiçoamento de Pessoal de Nível Superior - CAPES anualmente.

Foram analisados dois relatórios de uma mesma aluna bolsista do PIBID Matemática em dois anos subsequentes, sendo o primeiro relatório do $2^{\circ}$ semestre de 2014 e o segundo, do $1^{\mathrm{O}}$ semestre de 2015. Para tal análise, consideramos as sínteses didáticas e a parte inicial do relatório em que a bolsista expõe as contribuições do PIBID para sua própria formação, para os estudantes e para a escola.

No subprojeto analisado, as sínteses didáticas se referem às narrativas escritas individualmente pelos PIBIDianos, descrevendo a aplicação do plano de aula elaborado em conjunto e suas reflexões sobre as dificuldades dos alunos e suas próprias dificuldades na execução do mesmo na Escola Básica, evidenciando suas aprendizagens da docência nesse processo.

Foi adotada a análise textual discursiva de Moraes (2003). Esse tipo de análise é qualitativa, tendo em vista que “(...) a pesquisa qualitativa pretende aprofundar a compreensão dos fenômenos que investiga a partir de uma análise rigorosa e criteriosa desse tipo de informação" (MORAES, 2003, p. 191).

Inicialmente, examinamos os relatórios escolhidos, minuciosamente, e os fragmentamos, em busca de unidades relacionadas com o objetivo da pesquisa. Buscamos reunir tais unidades que eram semelhantes entre si, em categorias estabelecidas a priori, com base no instrumento de análise da prática docente de Arruda, Lima e Passos (2011). 
Em seguida, realizamos o tratamento dos resultados e produzimos sínteses, que permitem a compreensão do significado de cada categoria, com apoio de exemplos retirados do próprio corpus.

\section{Referencial Teórico}

Guarnieri (2005) afirma que algumas dimensões do trabalho docente apenas são percebidas a partir da prática profissional: “...uma parte da aprendizagem da profissão docente só ocorre e só se inicia em exercício" (p. 9). De modo a entender melhor esse processo de tornar-se professor, citado por Guarnieri (2005), buscamos nos estudos de Charlot e Chevallard (como citados por ARRUDA, LIMA E PASSOS, 2011) os fundamentos para analisar a ação docente da licencianda durante sua passagem pelo PIBID.

Contudo, entendemos que a análise da ação docente é uma atividade complexa e que devemos realizar alguns recortes que podem levar a uma simplificação de tal análise, por outro lado definir categorias a posteriori também não garantiria que o retrato de toda a complexidade da ação.

Partimos então das ideias de Charlot (como citado por ARRUDA, LIMA E PASSOS, 2011, p. 143) sobre as funções do professor: gerir relações epistêmicas, pessoais e sociais com o saber (...); relações com o conteúdo disciplinar, com o ensino e com a aprendizagem dos alunos.

Tais ideias são concordantes com as de Chevallard (como citado por ARRUDA, LIMA E PASSOS, 2011) que define um sistema didático constituído pelo professor, pelos estudantes e pelo saber e suas inter-relações.

Partindo dos pressupostos desses dois autores, Arruda, Lima e Passos (2011) produziram um instrumento para a análise docente que relaciona aquelas funções do professor identificadas por Charlot ao sistema didático definido por Chevallard, como mostra a Tabela 1. 
Tabela 1: Categorias para a análise da ação docente em sala de aula

\begin{tabular}{|c|c|c|c|}
\hline Tipo de & $\begin{array}{c}\mathbf{1} \\
\text { Gestão do segmento P- } \\
\mathbf{S} \\
\text { (conteúdo) }\end{array}$ & $\begin{array}{c}\mathbf{2} \\
\text { Gestão de segmento } \\
\text { P-E } \\
(\text { ensino })\end{array}$ & $\begin{array}{c}\mathbf{3} \\
\text { Gestão de segmento E-S } \\
\text { (aprendizagem) }\end{array}$ \\
\hline $\begin{array}{c}\text { A } \\
\text { Epistêmica }\end{array}$ & $\begin{array}{l}\text { Setor 1A } \\
\text { Diz respeito ao conteúdo } \\
\text { enquanto objeto a ser } \\
\text { compreendido } \\
\text { professor. }\end{array}$ & $\begin{array}{l}\text { Setor } 2 \mathrm{~A} \\
\text { Diz respeito ao ensino } \\
\text { enquanto atividade a ser } \\
\text { compreendida pelo professor. }\end{array}$ & $\begin{array}{llr}\text { Setor 3A } & & \\
\text { Diz respeito } & \text { à } \\
\text { aprendizagem } & \text { enquanto } \\
\text { atividade } & \text { a } & \text { ser } \\
\text { compreendida } & & \text { pelo } \\
\text { professor. } & & \end{array}$ \\
\hline $\begin{array}{c}\text { B } \\
\text { Pessoal }\end{array}$ & $\begin{array}{l}\text { Setor } 1 \mathrm{~B} \\
\text { Diz respeito ao conteúdo } \\
\text { enquanto objeto pessoal. }\end{array}$ & $\begin{array}{l}\text { Setor } 2 \mathrm{~B} \\
\text { Diz respeito ao ensino } \\
\text { enquanto atividade pessoal. }\end{array}$ & $\begin{array}{l}\text { Setor } 3 \mathrm{~B} \\
\text { Diz respeito à } \\
\text { aprendizagem enquanto } \\
\text { atividade pessoal. }\end{array}$ \\
\hline $\begin{array}{c}\text { C } \\
\text { Social }\end{array}$ & $\begin{array}{l}\text { Setor } 1 \mathrm{C} \\
\text { Diz respeito ao conteúdo } \\
\text { enquanto objeto social. }\end{array}$ & $\begin{array}{l}\text { Setor } 2 \mathrm{C} \\
\text { Diz respeito ao ensino } \\
\text { enquanto atividade social. }\end{array}$ & $\begin{array}{l}\text { Setor } 3 \mathrm{C} \\
\text { Diz respeito à } \\
\text { aprendizagem enquanto } \\
\text { atividade social. }\end{array}$ \\
\hline
\end{tabular}

Fonte: Arruda, Lima e Passos (2011, p. 147).

Apresentamos cada um dos setores da Tabela 1 exemplificados com excertos do Corpus analisado, que foram classificados na presente pesquisa:

Setor 1A. Diz respeito à relação epistêmica do professor com o conteúdo; às maneiras como dele se apropria e a busca por compreendê-lo cada vez mais; à relação com os objetos e os locais onde o conteúdo pode ser encontrado, como livros, revistas, vídeos, internet, biblioteca, universidades; etc.

Não foram encontrados excertos que pudessem ser classificados nesta categoria. O relatório da orientadora do grupo, que não é objeto de análise deste artigo, relata, entretanto, que os licenciandos em todos os semestres liam e discutiam as diretrizes curriculares (Parâmetros Curriculares Nacionais e Currículo do Estado de São Paulo), além dos relatórios pedagógicos do Sistema de Avaliação de Rendimento Escolar do Estado de São Paulo (SARESP) para cada série em que atuariam, bem como realizavam buscas de objetos educacionais virtuais como vídeos, simulações e jogos nos sites da Educopedia (www.educopedia.com.br), do M3 UNICAMP (www. m3.ime.unicamp.br), Domínio Público (http://portal.mec.gov.br/dominio-publico) e RIVED (http://rived.mec.gov.br/).

Setor 1B. Diz respeito à relação pessoal do professor com o conteúdo; ao sentido que o conteúdo adquire para ele e o quanto determina sua identidade profissional; a quanto o 
professor gosta e se envolve com a matéria que ensina; a como ele avalia sua própria compreensão da mesma; etc.

Todos esses desafios vencidos diariamente me preparam para vencer possíveis obstáculos, no futuro. (Contribuição do Projeto para a minha formação/2014)

[esta aula] foi bem produtiva, pois eu acredito que uma aula de exercícios sempre é ótima para praticar aquilo que foi ensinado. ( $1^{\circ}$ Bimestre/2015)

Setor 1C. Diz respeito aos conteúdos escolares, enquanto objeto de trocas sociais em uma comunidade específica; a quanto o professor partilha de uma comunidade de educadores e dos eventos que esta realiza; à sua relação com as pessoas que detêm o conhecimento; às suas identificações e ideais; à sua busca por aperfeiçoamento por meio do convívio com outros professores, participação em cursos; etc.

Juntamente com minha parceira de aulas, LM, estamos sempre discutindo novas ideias para os próximos semestres serem ainda melhores. (Contribuição do Projeto para a minha formação/2014)

Estive presente no Planejamento da Escola Estadual APM (...). Essas reuniões contribuíram para (...) entendermos como é feito um planejamento, conhecer melhor o projeto político pedagógico das escolas em que atuamos pelo PIBID, além das questões do SARESP, questões administrativas da escola, regras escolares e educação especial. (Contribuição do Projeto para a minha formação/2015)

Ao participar da semana da matemática consegui entender a importância dada à brincadeira para o ensino da matemática, pois ela é vista como uma fonte de conhecimentos, onde a criança constrói seus saberes matemáticos de forma significativa através do brincar. (Contribuição do Projeto para a minha formação/2015)

Setor 2A. Diz respeito à relação epistêmica do professor com o ensino; à sua busca por compreendê-lo melhor e às suas reflexões sobre a atividade docente e sobre a formação do professor; à sua percepção e reflexões sobre o seu próprio desenvolvimento como professor; às maneiras como realiza, avalia e procura melhorar o ensino que pratica; à sua relação com os materiais instrucionais, experimentos, instrumentos; às maneiras como realiza o planejamento dos objetivos, conteúdos, atividades, avaliação, recursos materiais; etc.

Para o próximo plano, quero ler alguns métodos de ensino e avaliar o que mais se enquadra para o ensino fundamental. ( $1^{\circ}$. Bimestre/2015)

Estive até pensando, que no caso de salas mais complicadas, talvez o ideal seja aplicar dinâmicas e jogos como forma de avaliar se eles entenderam ou não os conceitos. $\left(2^{\circ}\right.$. Bimestre/2015) 
Conversando com minha colega de aula, LM, chegamos à conclusão que teríamos que tirar alguns itens do proposto no plano, já que teria apenas mais duas aulas e não conseguiríamos passar o vídeo, aplicar o jogo dos 3M's e nem introduzir mediana. ( $2^{0}$. Bimestre/2015)

Setor 2B. Diz respeito à relação pessoal do professor com o ensino; a como se autoavalia como professor e como trabalha suas inseguranças; ao sentido pessoal que atribui ao ato de ensinar e o quanto isso influi em sua identidade profissional; ao quanto ele gosta de ensinar; ao seu estilo como professor e ao modo pessoal de se relacionar e aplicar as regras e normas de conduta; às responsabilidades, valores que se imputa enquanto educador; etc.

Fiquei bem contente ao ver o aluno que acompanhei nessas aulas, com a síndrome já citada [Asperger], fazer com tanta dedicação as questões. $\left(1^{\circ}\right.$ bimestre/2015)

Erramos sim, talvez o plano tenha muito conteúdo! Ou, já que as salas eram complicadas, deveríamos ter passado o vídeo e aplicado o jogo como forma de aplicar o conhecimento. Entretanto, ao mesmo tempo, penso que poderia não surtir efeito e eles precisam aprender os conceitos e não apenas brincarem. ( $2^{\circ}$. Bimestre/2015)

Setor 2C. Diz respeito ao ensino enquanto atividade social e interativa; às dificuldades e inseguranças pessoais produzidas em decorrência da interação com os outros (alunos, pais, professores, administradores, etc.); às habilidades do professor para negociar com os alunos valores e comportamentos para que consiga ensinar e gerenciar o funcionamento da sala de aula; aos esforços que ele faz para conseguir apoio dos demais agentes sociais, cujas opiniões e avaliações afetam sua segurança, posição e sua autoridade enquanto professor; etc.

Mesmo a direção conseguindo resolver a situação e nos ceder a sala de vídeo, isso custou uns 20 minutos dessa aula, o que comprometeu a realização do plano que deveria ser realizado neste dia. ( $4^{\circ}$ bimestre/2014)

Como tínhamos dúvidas, pois queríamos aplicar o vídeo para o $8^{\circ} \mathrm{A}$ e o jogo para o $8^{\circ} \mathrm{B}$, pedimos ajuda para nossa orientadora, que nos auxiliou e explicou que o adequado era ensinar mediana, já que eles iriam precisar desse conteúdo mais para frente. $\left(2^{\mathrm{o}}\right.$. Bimestre/2015)

Setor 3A. Diz respeito à relação epistêmica do professor com a aprendizagem; à sua busca por compreender as maneiras como os alunos a realizam; à sua percepção e reflexão sobre as relações dos alunos com os conteúdos, às ideias prévias dos alunos e suas dificuldades de aprendizagem; etc.

(...) podíamos perceber exatamente a diferença de um aluno que se dedicava e tentava fazer os exercícios, mas que tinha vergonha de perguntar quando não sabia, de um aluno que não parava quieto a aula toda, tendo que chamar 
a atenção várias vezes, sendo que nem assim adiantava, não queria fazer as atividades. ( $1^{\circ}$. Bimestre/2015)

(...) grande problema dos alunos é a dificuldade de interpretar textos e saber transpor para uma linguagem diferente. (10. Bimestre/2015)

(...) infelizmente, os alunos em geral não estão acostumados a ler pequenos textos, por conta das redes sociais atuais. (10. Bimestre/2015)

Setor 3B. Diz respeito: à relação pessoal do professor com a aprendizagem de seus alunos; ao sentido que esta adquire e o quanto determina sua identidade profissional; às preocupações do professor com o envolvimento, motivação e interesse dos alunos e com a qualidade das interações na sala de aula; à sua capacidade pessoal de interferir e gerenciar a relação dos alunos com o conteúdo; etc.

Percebemos que por mais que atrasamos metade de uma aula pela dificuldade deles, surtiu resultado, pois o importante é a compreensão dos conceitos já dados e não cumprir o currículo. (1 $1^{\circ}$ Bimestre/2015)

(...) um [aluno] que nas duas primeiras aulas não prestava atenção, conversava durante nossa explicação e olhava com cara feia para nós. No final da segunda aula, peguei para conversar com ele sobre a nossa função e a nossa vontade de vê-los entender o que tanto eles "detestam". Disse a ele que não estávamos por maldade cobrando a compreensão deles, mas sim tentando ensinar de um jeito mais dinâmico (...). Na terceira aula surtiu grande efeito aquela conversa e nunca o vi tão dedicado e prestando atenção no que explicávamos, além de uma melhora na socialização com os outros alunos. ( $1^{\circ}$ Bimestre/2015)

Setor 3C. Diz respeito: à aprendizagem enquanto atividade social e interativa; à manutenção de um ambiente propício às interações e à aprendizagem dos alunos; ao gerenciamento dos trabalhos e demais atividades em grupos; etc.

Para a próxima aula, para o rendimento melhorar, vou propor de misturar a classe para perder essa "rotulação" de certos alunos que acabam ficando desmotivados a fazerem listas ou até mesmo de aprender. $\left(2^{\circ}\right.$ Bimestre/2015)

Além disso, não esperarei tanto tempo para resolver com eles os exercícios, pois eles aproveitam para conversar e perdem o foco, atrasando o rendimento da aula.. ( $2^{\circ}$ Bimestre/2015)

\section{Análise dos dados}

Encontramos dificuldade em classificar alguns fragmentos dentro das nove categorias, principalmente devido a alguns serem formados por muitas orações, dando a ideia de que expressavam mais de uma categoria, porém, buscou-se classificar de acordo com 
aquilo que era o cerne do fragmento. Nos dois anos analisados, encontramos quase a mesma quantidade de fragmentos, 236 em 2014 e 231 em 2015.

A Tabela 2 apresenta a distribuição dos fragmentos de acordo com as categorias do instrumento de análise da ação docente.

Tabela 2: Distribuição dos fragmentos extraídos dos relatórios de 2014 e 2015

\begin{tabular}{|c|c|c|c|c|}
\hline & \multicolumn{2}{|r|}{2014} & \multicolumn{2}{|r|}{2015} \\
\hline Classificação & $\boldsymbol{F}$ & Porcentagem & $\boldsymbol{F}$ & Porcentagem \\
\hline Relação Epistêmica na Gestão de Conteúdo (1A) & $\mathrm{O}$ & $0 \%$ & o & $0 \%$ \\
\hline Relação Pessoal na gestão de Conteúdo (1B) & 1 & $0,4 \%$ & 2 & $0,9 \%$ \\
\hline Relação Social na Gestão de Conteúdo (1C) & 1 & $0,4 \%$ & 2 & $0,9 \%$ \\
\hline Relação Epistêmica na Gestão do Ensino (2A) & 72 & $30,5 \%$ & 62 & $26,8 \%$ \\
\hline Relação Pessoal na Gestão do Ensino (2B) & 10 & $4,2 \%$ & 18 & $7,8 \%$ \\
\hline Relação Social na Gestão do Ensino (2C) & 17 & $7,2 \%$ & 22 & $9,5 \%$ \\
\hline $\begin{array}{l}\text { Relação Epistêmica na Gestão da Aprendizagem } \\
(3 \mathrm{~A})\end{array}$ & 66 & $28,0 \%$ & 68 & $29,4 \%$ \\
\hline Relação Pessoal na Gestão da Aprendizagem (3B) & 50 & $21,2 \%$ & 32 & $13,9 \%$ \\
\hline Relação Social na Gestão da Aprendizagem (3C) & 19 & $8,1 \%$ & 25 & $10,8 \%$ \\
\hline TOTAL & 236 & $100 \%$ & $\mathbf{2 3 1}$ & $100 \%$ \\
\hline
\end{tabular}

Fonte: Autoria Própria

Observamos uma incidência baixíssima nas linhas que se referem a gestão do conteúdo, nos dois anos analisados, o que é concordante com os resultados de Passos, Passos e Arruda (2017). Acreditamos que o fato da licencianda ser oriunda de uma Instituição de Ensino Superior pública renomada, pode ter contribuído para que o conteúdo não fosse um motivo de preocupação, ou que merecesse reflexões em seus relatórios. Em geral, os maiores problemas enfrentados na sala de aula pelos professores egressos de Instituições como a da 
pesquisada, não são o conteúdo em si, mas como transmitir tal conteúdo, o que fica claro nos relatórios.

Por outro lado, observamos a maior incidência de fragmentos sobre a gestão da aprendizagem (57,3\% em 2014 e 54,1\% em 2015). Esse resultado é discordante dos levantados por Passos, Passos e Arruda (2017) que afirmam que a frequência maior de fragmentos, nas pesquisas na formação inicial de professores, depois que a matriz foi criada, vem incidindo na gestão de ensino:

(...) a preocupação com o conteúdo é praticamente inexistente (pelo menos não ficaram explícitas nos relatos) e a preocupação com o aprendizado dos alunos é pequena (...). Essa conclusão também tem sido sugerida por contatos gerais que temos tido tanto com professores em formação quanto com professores experientes. Os professores aparentemente estão mais preocupados com o gerenciamento do ensino do que com o gerenciamento da aprendizagem (p. 157).

Ponderamos que a análise dos relatórios que contêm as sínteses didáticas das experiências em sala de aula, da presente pesquisa é de apenas uma bolsista do Programa PIBID de uma Instituição e que parte do motivo da escolha dos relatórios desta licencianda se deu pela qualidade da reflexão sobre a prática que a mesma fazia. Porém, acreditamos que esses dados sugerem uma contribuição do PIBID muito positiva com relação a preocupação, não somente com a gestão do ensino, mas principalmente com a gestão da aprendizagem dos estudantes, o que certamente acarretará numa melhor formação inicial.

Aparentemente o PIBID contribuiu para um equilíbrio da preocupação na ação docente em relação a gestão do ensino e a gestão da aprendizagem, entendendo que ambas são importantes na prática docente.

A preocupação com a gestão da aprendizagem dos estudantes por parte da licencianda foi expressa em diversos fragmentos, como o excerto a seguir mostra:

Como em todas as aulas, o $7^{\circ} \mathrm{CC}$ foi bem participativo e os alunos perguntavam tudo o que eles tinham dúvidas, como por exemplo, a interpretação e construção de gráficos, interpretação do enunciado para fazer soma, diferença ou total (3A). Percebemos o interesse deles e a felicidade por terem ido bem na atividade (3B). Entretanto, alguns alunos do fundo conversaram bastante, acho que é pelo fato da aula ter sido com exercícios, pois quando eram faladas coisas dos seus interesses (vídeo), eles nem conversavam (3B). Percebemos que nos slides relacionados ao anime os alunos se divertiram bastante e até pediram para passarmos mais episódios relacionados aos dados de gráficos e tabelas. Entretanto explicamos que não tínhamos mais tempo (3C). A média da sala na atividade 3 foi de $8,0(3 \mathrm{~A})$. Desempenhamo-nos ao máximo para que cada aula fosse divertida e que atraísse a atenção deles $(3 \mathrm{~B})$. Por ser nosso primeiro bimestre, considero que tivemos certos pontos positivos que nos ajudaram a incentivá-los e, além disso, nos respeitarem (2A). As duas salas apresentaram certos problemas no ISSN 2526-2882 
início das aulas, mas posso dizer que eles tentavam ao máximo se esforçar e entenderem (3A). Os próprios alunos valorizavam as aulas diferenciadas que aplicávamos e elogiavam $(3 \mathrm{C})\left(3^{\circ}\right.$ bimestre/2014).

Além das reflexões sobre a aprendizagem dos estudantes, seus interesses e motivações, também se observa uma constante reflexão sobre a própria prática, sua identificação com a docência, frustrações e motivações pessoais, como mostram os relatos:

\begin{abstract}
Faltando 40 minutos, avisamos que aplicaríamos uma pequena avaliação para vermos se eles entenderam bem a matéria dada. Nenhum aluno reclamou e todos começaram a fazer $(2 \mathrm{C})$. Quando faltavam 5 minutos todos tinham terminado, e com isso entregamos as listas da atividade da aula 3 e a da revisão para verem suas notas, e falamos que a nota da prova entregaríamos na sexta feira para a professora (2A). Os alunos nos agradeceram e nos aplaudiram na nossa despedida (2B). Fiquei bem feliz com o fato de eles valorizarem todo o aprendizado que pudemos oferecer e me disponibilizei sempre que eles precisassem me procurassem $(2 \mathrm{~B}) \cdot\left(3^{\circ}\right.$ bimestre/2014)

Este foi um bimestre bem complicado de lidar (2A). (...) Em cada aula tentei dar o meu melhor, levando slides e até mesmo folhas com o conceito no caso deles não quererem acompanhar por ppt, mas sinto que meu melhor não foi o suficiente para essas duas classes (2B). (...) Se tudo isso fez eu desanimar da profissão de professor? (2A) Não, apenas me deu mais vontade e determinação para ampliar meus estudos nesses meses, onde procurarei novas ideias para planos de aulas e novos métodos para lidar com os alunos (2B). Estive até pensando que no caso de salas mais complicadas, talvez o ideal seja aplicar dinâmicas e jogos como forma de avaliar se eles entenderam ou não o conceito $(2 \mathrm{~A}) .\left(2^{\mathrm{O}}\right.$ bimestre/2015)
\end{abstract}

Observamos ainda que os dados da Tabela 2 nos revelam que no que diz respeito ao tipo de relação estabelecida com o saber, as de caráter epistêmico se sobressaem $(58,5 \%$ em 2014 e 56,2\% em 2015). Acreditamos que isso possa ser explicado pelo fato do PIBID proporcionar diversos momentos e oportunidades de reflexão sobre a natureza do objeto ou da atividade que faz parte da docência, corroborando os dados de Correia (2012). Era nítido o tom reflexivo da licencianda em diversos pontos de sua síntese, ao tecer observações e avaliações sobre sua "prática docente".

Entende-se, então, o PIBID como uma oportunidade para refletir não somente sobre a gestão do ensino, mas também sobre a gestão da aprendizagem dos estudantes. $\mathrm{O}$ desenvolvimento desta capacidade é de grande importância, como destacado pelas Diretrizes Curriculares para Cursos de Matemática: é desejável que um licenciado em matemática tenha uma “...visão de seu papel social de educador e capacidade de se inserir em diversas realidades com sensibilidade para interpretar as ações dos educandos” (BRASIL, 2001, p. 3).

Outra característica almejada em um licenciado em Matemática de acordo com as Diretrizes é a “...visão da contribuição que a aprendizagem da Matemática pode oferecer à formação dos indivíduos para o exercício de sua cidadania” (BRASIL, 2001, p. 3). ISSN 2526-2882 
Observamos tal visão da licencianda em seus relatórios e destacamos um excerto que mostra sua preocupação em tornar a Matemática ensinada em algo que é prático para a vida do estudante, no caso, para interpretar textos e organizar o pensamento:

Em seguida, discutimos sobre a importância da tabela e mostramos que essa é muito usada hoje em dia para interpretação de dados que muitas vezes estão em forma de texto e, além disso, nossos pensamentos ficam mais organizados, tornando-os mais fácil para usar os dados em somatória, diferença ou qualquer operação matemática (1A). ( $3^{\circ}$ bimestre/2014)

E finalmente, o reconhecimento “...de que o conhecimento matemático pode e deve ser acessível a todos, e consciência de seu papel na superação dos preconceitos, traduzidos pela angústia, inércia ou rejeição, que muitas vezes ainda estão presentes no ensinoaprendizagem da disciplina" (p. 3), também esteve presente nos relatórios, como se observa no excerto a seguir:

Nesta sala já notamos a presença de um aluno hiperativo e outro com Síndrome de Asperger (3A). Durante a aula eu e minha parceira, LM, revezávamos para ficar uma com esses dois e a outra com o restante da sala, pois eles queriam atenção só para eles, e na hora de exercícios tínhamos que estimular o aluno com síndrome de Asperger a fazê-los (3B). $\left(1^{\mathrm{o}}\right.$ bimestre/2015)

Ao analisarmos as competências e habilidades específicas de um educador matemático, preconizadas pelas Diretrizes (BRASIL, 2001, p. 4), pudemos encontrar excertos que parecem indicar que o PIBID tem contribuído com o desenvolvimento de todas.

Observamos o uso de diversas estratégias de ensino nos registros da licencianda, a saber: competições, uso de slides atrativos, desafios com personagens do universo dos estudantes, aulas expositivas e dialogadas, uso de jogos, dinâmicas que previam a participação ativa dos estudantes e utilização de vídeos. Consideramos que essas estratégias, que incorporam o uso das TIC, dizem respeito às competências de elaborar propostas de ensino-aprendizagem de Matemática para a educação básica; e, analisar, selecionar e produzir materiais didáticos:

O vídeo era um trecho de um anime (Death Note), que continha alguns dados nos quais serão usados em uma apresentação de slides onde revisaremos o conteúdo já dado para podermos passar para interpretação de gráfico de setores $(2 \mathrm{~A}) .\left(3^{\circ}\right.$ bimestre/2014)

Para as próximas aulas continuaremos com vídeos e slides chamativos (2A) para ver se prendemos a atenção deles (3B). (4 $4^{\circ}$ bimestre/2014) 
No $6^{\circ} \mathrm{C}$, conseguimos aplicar o jogo com o uso de vídeo e apresentação de slides (2A). ( $1^{\mathrm{O}}$ bimestre/2015)

Juntamente com minha parceira de aulas, LM, estamos sempre discutindo novas ideias para os próximos semestres serem ainda melhores $(1 \mathrm{C}) .(\ldots)$ Todos esses desafios vencidos diariamente me preparam para vencer possíveis obstáculos, no futuro (1B). (Contribuição do Projeto para a minha formação/2014)

A contribuição para a competência de analisar criticamente propostas curriculares de Matemática para a educação básica pode ser identificada no excerto:

Tais aulas tiveram como base o estudo dos PCN's (BRASIL, 1998) e do Currículo do Estado de São Paulo (SÃO PAULO, 2013) e foram aplicadas em uma escola pública estadual do interior do Estado de São Paulo, no âmbito do Programa Institucional de Bolsas de Iniciação à Docência (PIBID - Nome da Instituição). ( $1^{\circ}$ bimestre/2015)

O excerto do $4^{\circ}$ Bimestre/2014 é um dos indícios da capacidade de desenvolver estratégias de ensino que favoreçam a criatividade, a autonomia e a flexibilidade do pensamento matemático dos educandos, buscando trabalhar com mais ênfase nos conceitos do que nas técnicas, fórmulas e algoritmos:

Ao final do PowerPoint e das atividades, mostramos um vídeo editado com o desenho animado "Cyberchase", cujo tema é contagem e probabilidade no cotidiano, a cada jogo mostrado fazíamos uma pausa e perguntávamos se aquele jogo era justo ou não e como faríamos para saber $(2 \mathrm{~A}) \cdot\left(4^{\mathrm{o}}\right.$ bimestre/2014)

A competência de perceber a prática docente de Matemática como um processo dinâmico, carregado de incertezas e conflitos, um espaço de criação e reflexão, onde novos conhecimentos são gerados e modificados continuamente, pode ser percebida no excerto que se segue:

Conversando com eles, percebi que estes ficaram bem animados com aula na sala de vídeo, além de acharem muito legal os slides com imagens dos Simpsons (3B). Realmente pensei que esta sala seria um pouco mais complicada em relação à outra, porém hoje esse "medo" passou, pois foi uma aula boa e bem dinâmica $(2 \mathrm{C})$. Para as próximas, buscarei usar o mesmo método que nessas, utilizando bastante animações e sala de vídeo (2A). Sobre a matéria em si, esta sala tem mais facilidade, porém não há nada que impeça de até a aula 5 conseguirmos isso com o outro sétimo ano $(3 \mathrm{~B}) .\left(3^{\circ}\right.$ bimestre/2014)

Sendo o PIBID um Programa que envolve a Universidade e a escola, com propositura de atividades diferenciadas elaboradas a muitas mãos e com o objetivo de 
ensinar conteúdos, procedimentos e atitudes, parece evidente a sua contribuição para o desenvolvimento da competência do futuro professor de realizar projetos coletivos para a escola básica.

\section{Considerações Finais}

A análise dos relatórios de dois semestres consecutivos de uma licencianda em Matemática, participante do Programa Institucional de Bolsas de Iniciação à Docência de uma Instituição de Ensino Superior pública do estado de São Paulo evidenciou que o Programa expôs a licencianda a uma série de atividades com grandes potencialidades para a aprendizagem da docência da mesma.

Foram identificados nos relatórios indícios de desenvolvimento ou aperfeiçoamento das características almejadas para um futuro educador, preconizadas pelas Diretrizes Curriculares para Cursos de Matemática e pelas exigências atuais da sociedade tecnológica.

O uso do instrumento de análise da ação docente (ARRUDA, LIMA E PASSOS, 2011) apontou uma quase ausência de reflexões sobre a gestão de conteúdo o que se mostrou concordante com outros estudos realizados com tal instrumento. Contudo, também foi observado um equilíbrio de reflexões sobre a gestão de ensino e a gestão da aprendizagem, que é em parte, discordante de outros estudos realizados com licenciandos, em que se sobressaiu a preocupação com a gestão do ensino apenas.

Consideramos esse resultado muito positivo, uma vez que acreditamos que um bom ensino deve necessariamente produzir aprendizagens. Pensar a prática docente é tão importante quanto refletir se os estudantes estão aprendendo e desenvolvendo o seu pensamento matemático.

O tipo de relação com o saber mais percebida nas narrativas da licenciada foi a epistêmica evidenciando uma contribuição do PIBID para a reflexão de diversas naturezas, corroborando os estudos de Tinti (2012) e Correia (2012).

Concluímos que PIBID parece contribuir para a qualificação do futuro professor da educação básica. Ao aproximar a Universidade e a Escola, ele oportuniza ao licenciando vivenciar o seu futuro campo de atuação e aprender a partir desse, integrando assim, teoria e prática. Sendo assim, entendemos que, há indícios de ocorrência de uma verdadeira qualificação do ensino e da aprendizagem dos alunos.

Finalizando, neste momento em que o PIBID, um programa de formação inicial de professores considerado inovador, sofre alguns reveses e reformulações, esperamos que a identificação de suas contribuições, potencialidades e dificuldades, possa conduzir a uma reformulação mais adequada aos objetivos do mesmo pela CAPES. 


\section{Referências}

AMBrosetTI, N. B.; DE ARRUdA, M. D. G. C.; ALMEIDA, P. A.; CALIL, A. M. G. C.; PASSOS, L. F. Contribuições do Pibid para a formação inicial de professores. Educação em Perspectiva, Viçosa, v. 4, n. 1, p. 151-174, jan./jun. 2013.

ANDRÉ, M. E. D. A.; SIMÕES, R.; CARVALHO, J. M.; BRZEZINSKI, I. Estado da arte da formação de professores no Brasil. Educação e Sociedade, Campinas: Cedes, v. 20, n. 68, p. 301-309, 1999.

ARRUDA, S. M.; LIMA, J. P. C.; PASSOS, M. M. Um novo instrumento para a análise da ação do professor em sala de aula. Revista Brasileira de Pesquisa em Educação e Ciências, São Paulo, v. 11, n. 2, p. 139-160, 2011.

BEHREnS, M. A. Projetos de Aprendizagem Colaborativa num Paradigma Emergente. In: Novas Tecnologias e Mediação Pedagógica. Campinas: Papirus, p. 73-140, 2013.

BOGDAN, R. C.; BIKLEN, S. K. Investigação qualitativa em educação. Porto: Porto Editora, 1994.

BRASIL. Ministério da Educação. Conselho Nacional de Educação. Diretrizes Curriculares Nacionais para os Cursos de Matemática, Bacharelado e Licenciatura. Brasília: MEC/CNE/CES, 2001. Disponível em: <http://portal.mec.gov.br/cne/arquivos/pdf/CES13022.pdf>. Acesso em: jun. 2010. CALDERANO. O Estágio Supervisionado Para Além De Uma Atividade Curricular: Avaliação E Proposições. Estudos em Avaliação Educacional, São Paulo, v. 23, n. 53, p. 250-278, set/dez. 2012.

CANAN, S. R. PIBID: promoção e valorização da formação docente no âmbito da Política Nacional de Formação de Professores. Revista Brasileira de Pesquisa sobre Formação de Professores, Belo Horizonte, v. 04, n. 06, p. 24 - 43, jan./jul. 2012.

CORREIA, G. S. Estudo dos conhecimentos evidenciados por alunos dos cursos de licenciatura em Matemática e Física participantes do PIBID-PUC/SP. 2012. 128 f. Dissertação (Mestrado em Educação Matemática) - Pontifícia Universidade Católica de São Paulo, São Paulo, 2012.

CURI, E. Formação de professores de matemática: realidade presente e perspectivas futuras. 2000. 241p. Dissertação (Mestrado em Educação Matemática) - Centro de Ciências Exatas e Tecnologia, Pontifícia Universidade Católica, São Paulo, 2000. 
DOS SANTOS FELÍCIO, H. M. O PIBID como "terceiro espaço" de formação inicial de professores. Revista Diálogo Educacional, Curitiba, v.14, n. 42, p. 415 - 434, maio/ago. 2014 .

FREITAS, M. T. M. Estágio curricular em Matemática na perspectiva de extensão universitária: estudo de uma experiência na UFU. 2000. 165f. Dissertação (Mestrado em Educação) - Faculdade de Educação, Universidade Federal de Uberlândia, Uberlândia, 2000.

FREITAS, M.T.M.; FIORENTINI, D. As possibilidades formativas e investigativas da narrativa em educação matemática. Horizontes, v.25, n.1, p. 63-71, jan/jun. 2007.

FREITAS, M.T.M.; FIORENTINI, D. Desafios e potencialidades da escrita na formação docente em Matemática. Revista Brasileira de Educação, v.13, n.37, p. 138-189, jan/abr. 2008.

GATTI, B.A. (Org.). Análises pedagógico-curriculares para os cursos de licenciatura vinculados às áreas de artes, biologia, história, língua portuguesa, matemática e pedagogia no âmbito da UAB e PARFOR. Documento Técnico. Brasília: Unesco/MEC/Capes, 2012.

GATTI, B. A. Formação inicial de professores para a educação básica: pesquisas e políticas educacionais. Estudos em Avaliação Educacional, São Paulo, v. 25, n. 57, p. 2454, jan./abr. 2014.

GATTI, B. A.; BARRETO, E. S. Professsores do Brasil: impasses e desafios. Brasília. UNESCO, 2009. Disponível em: http://pt.scribd.com/doc/22429760/Professoresdo-Brasil

GUARNIERI, M. R. O início da carreira docente: pistas para o estudo do trabalho do professor. In: GUARNIERI, M. R. (Org.). Aprendendo a ensinar: o caminho nada suave da docência. Campinas, SP: Autores Associados, Faculdade de Ciências da UNESP, 2005.

LESSARD, C. A universidade e a formação profissional dos docentes: novos questionamentos. Educação e Sociedade, Campinas, v,27, n.94, p. 202-227, 2006. Disponível em: http://www.scielo.br/pdf/es/v27n94/a11v27n94.pdf

MORAES, R. Uma tempestade de Luz: a compreensão possibilitada pela análise textual discursiva. Ciência \& Educação, v. 9, n. 2, p. 191-211, 2003.

NEITZEL, A. A.; FERREIRA, V. S.; COSTA, D. Os impactos do Pibid nas licenciaturas e na educação básica//The impacts of Pibid in licensure and in Basic Education. CONJECTURA: filosofia e educação, Caxias do Sul, v. 18, n. especial, p. 98 121, 2013. 
OBARA, C. E.; BROIETTI, F. C. D.; PASSOS, M. M. Contribuições do PIBID para a construção da identidade docente do professor de Química. Ciencia \& Educação, Bauru, v. 23, n. 4, p. 979-994, 2017.

PASSOS, A. M.; PASSOS, M. M.; ARRUDA, S. M. Uma análise das ações do professor em uma sala de aula em que estão presentes estudantes com deficiência visual. Ciência \& Educação (Bauru), v. 23, n. 2, p. 541-546, 2017.

RASMUSSEM, J. It is not enough to be an expert in your field. Education Alliance Quaterly: teacher education, Denmark, p. 11-13, Aug. 2008.

RAUSCH, R. B.; FRANTZ, M. J. Contribuições do PIBID à formação inicial de professores na compreensão de licenciandos bolsistas. Atos de pesquisa em educação, v. 8, n. 2, p.620-641, mai./ago. 2013.

RODRIGUES, M. U.; MISKUlIN, R. G. S.; SILVA, L. D. Potencialidades do PIBID/Matemática para Formação de Professores no Brasil (Potential of the PIBID for the initial and continued formation of Mathematics teachers in Brazil). Crítica Educativa, Sorocaba/SP, v. 3, n. 2 - Especial, p. 573-590, jan./jun.2017.

SANTOS, S. A narrativa como estratégia de formação e reflexão sobre a prática docente. Teoria e Prática da Educação, v.11, n.2, p.207-217, maio/ago. 2008.

SILVA, G. M. Um estudo sobre o uso do Geogebra na aprendizagem de Geometria Analítica no Ensino Médio. Dissertação (Mestrado Profissional em Educação). São Carlos: UFSCAR, 2016.

TARDIF, M. Saberes docentes e formação profissional. 13. ed. Petrópolis: Vozes, 2002.

TINTI, D. S. PIBID: um estudo sobre suas contribuições para o processo formativo de alunos de Licenciatura em Matemática da PUC-SP. 2012. 148 f. Dissertação (Mestrado em Educação Matemática) - Pontifícia Universidade Católica de São Paulo, São Paulo, 2012.

VALENTE. J. A. Computadores e conhecimento: repensando a educação. Campinas. São Paulo: Gráfica Central da Unicamp, 1993.

ZAQUEU, A. C. M. O Programa Institucional de Bolsas de Iniciação à Docência (PIBID) na formação de professores de matemática: perspectivas de ex-bolsistas. 2014. $267 \mathrm{f}$. Dissertação (Mestrado em Educação Matemática) - Universidade Estadual Paulista “Júlio de Mesquita Filho”, Rio Claro, 2014. 


\section{Agradecimentos}

$\overline{\text { Agradecemos pelo financiamento à pesquisa fornecido pela FAPESP 2017/03183-0; FAEPEx- }}$ UNICAMP 2240/2017

\section{Biografia Resumida}

Ayla Moulaz Carvalho - licencianda em Matemática pela Universidade Estadual de Campinas (UNICAMP/Campinas).

Link do Lattes: http://lattes.cnpq.br/9958155643718612

e-mail: a.mcarvalho1004@gmail.com

Miriam Cardoso Utsumi - Licenciada em Matemática pela Universidade Estadual de Campinas (UNICAMP/Campinas). Mestre em Educação (UNICAMP/Campinas). Doutora em Educação Matemática (UNICAMP/Campinas). Professora e Pesquisadora (UNICAMP/Campinas). Orientadora do Mestrado Profissional em Educação (FE-UNICAMP) e do Mestrado e Doutorado do Programa de Pós-graduação Multiunidades em Ensino de Ciências e Matemática (PECIM-UNICAMP). Membro dos Grupos de Pesquisa PSIEM e GEPEMAI.

e-mail: mutsumi@g.unicamp.br

Link do Lattes: http://lattes.cnpq.br/7990278071583200 